\title{
Harry Potter e a Linguística de Corpus em aulas de língua inglesa para o ensino fundamental II
}

\author{
Elaine Cristina Oliveira* \\ Adriane Orenha Ottaiano"**
}

\section{Resumo}

$\mathrm{O}$ artigo descreve a realização de aulas de língua inglesa baseadas no primeiro livro e filme da saga escrita por Joanne Kathleen Rowling "Harry Potter and the Sorcerer's Stone" em corpora. A investigação utiliza postulados da Linguística de Corpus e Diretrizes do Ensino de Língua Estrangeira. O software WordSmith Tools, versão 6.0, foi utilizado para corroborar as informações dos dois corpora comparáveis (livro digitalizado e legendas do filme em formato eletrônico). Com base nas informações coletadas, elaborou-se um material composto por atividades que buscam o aprendizado da língua inglesa. Algumas dessas atividades foram aplicadas no curso de extensão (English for Teens), de uma universidade pública, cujo público alvo são alunos oriundos da escola pública, do Ensino Fundamental II.

Palavras-chave: Corpora. Língua Estrangeira. Metodologia. Harry Potter.

\section{Introdução}

A proposta apresentada neste artigo oferece uma metodologia diferenciada no ensino de inglês, a partir de textos e vídeos da própria língua alvo, notadamente o primeiro livro da série escrita por Joanne Kathleen Rowling (1997): Harry Potter and the Sorcerer's Stone.

$O$ tema é justificado pela necessidade, cada vez mais atual, do educador utilizar novas estratégias para se aproximar da

\footnotetext{
Mestranda em Estudos Linguísticos pela UNESP/ IBILCE - Universidade Estadual Paulista. São José do Rio Preto - Brasil. E-mail: elaininha.hta@hotmail.com

** Doutora em Estudos Linguísticos, Professora Universitária da UNESP - Universidade Estadual Paulista (IBILCE/UNESP). São José do Rio Preto - Brasil. E-mail: adrianeorenha@gmail.com
}

Data de submissão: jul. 2017 - Data de aceite: set. 2017 http://dx.doi.org/10.5335/rdes.v13i3.7182 
realidade do aluno em aulas de idiomas. Com o uso de temas interessantes e dinâmicos como mote, aproxima o estudante da língua estrangeira (doravante LE), notadamente na realização de propostas que se aproximam do seu cotidiano, conforme se verifica nos anexos deste trabalho.

Embora a Linguística de Corpus (LC) seja uma área do conhecimento em expansão no Brasil e no exterior (principalmente na Europa), várias faculdades nacionais não possuem, infelizmente, disciplinas e atividades de extensão com enfoque nesse conteúdo. Alegamos ainda, a utilidade em divulgar uma das pesquisas desenvolvidas no Grupo de Pesquisa "Pedagogia do Léxico e da Tradução e Linguística de Corpus”, já registrado no Diretório de Grupo de Pesquisas do CNPq. De cunho didático pedagógico, este texto pode oferecer de suporte para docentes de qualquer LE, que queira utilizar algumas das propostas apresentadas, ou então, adaptá-las à sua realidade e contexto adjacentes.

Inicialmente, este trabalho apresenta uma fundamentação teórica baseada em estudos já realizados na LC e sua contribuição para o ensino de línguas. Em seguida, encontram-se os procedimentos metodológicos para a realização da atividade, bem como introduzir e apresentar aos alunos os conceitos e finalidades da LC, além da análise dos dados baseados nos corpora coletados, bem como o desenvolvimento das atividades propostas e ministradas no curso de Extensão English for Teens, oferecido na Unesp (Câmpus de São José do Rio Preto - Ibilce) para a comunidade externa, sob coordenação da Profa. Dra. Adriane Orenha Ottaiano.

Por meio das atividades elaboradas, objetiva-se que o aluno possa: compreender o léxico formal da língua inglesa utilizado em cartas formais, ampliar o conhecimento vocabular, otimizando sua capacidade auditiva e escrita. Também esperamos transmitir algumas informações sobre a LC voltada ao ensino, mostrando aos discentes uma nova forma de aprender inglês. Dessa maneira, traçar comparações e paralelos da vida do adolescente protagonista (mostrada na ficção) com a sua própria, tecendo reflexões sobre o idioma alvo enquanto amplia o seu conhecimento cultural e linguístico.

\section{Fundamentação teórica}

Visto que o artigo versa sobre a aplicação da Linguística de Corpus (LC) em aulas de língua inglesa tendo como destaque o primeiro livro e filme da saga Harry Potter, os tópicos teóricos versam sobre a LC voltada ao ensino e produção de materiais didáticos para o ensino de LE, além de uma contextualização ao tema das práticas realizadas no curso de idiomas English for Teens, conforme segue.

Assim, torna-se pertinente discutir a definição de LC (apontando a sua importância como recurso teórico-metodológico 
para o ensino de línguas estrangeiras), e justificar a escolha do livro Harry Potter and the Sorcerer's Stone no desenvolvimento das atividades sugeridas neste artigo.

Dessa maneira, visamos descrever a motivação temática das aulas, oferecendo um panorama da teoria e do objeto de estudo que escolhemos para este trabalho.

\section{LC e LE, uma parceria profícua na elaboração de materiais de ensino}

A LC se destaca na Linguística Aplicada por analisar a linguagem a partir da compilação de dados reais de comunicação. Aliadas à informática e amparadas pelos softwares, são realizadas pesquisas quantitativas e qualitativas relevantes para a comunidade acadêmica, que também aplica suas descobertas ao público em geral.

Consequentemente, tal vertente possibilitou infinitos campos de estudos e pesquisa de dados reais, oferecendo outros olhares sobre a linguagem ${ }^{1}$. Teceremos no corrente texto, algumas considerações do uso de corpora no ensino de idiomas e na formulação de materiais de ensino.

Apesar de possuir legislações que regulamentam o ensino de LE no Brasil, Parâmetros Curriculares Nacionais (PCN), por exemplo, o próprio documento aponta para alguns problemas existentes na prática docente: falta de materiais adequados, classes excessivamente numerosas, número reduzido de aulas por semana, tempo insuficiente dedicado à matéria no currículo e ausência de ações formativas contínuas junto ao corpo docente (1998, p. 24).

É no cenário de emprego de novas tecnologias que a LC surge como ferramenta interessante. $\mathrm{O}$ professor de línguas tem, então, um suporte pedagógico que pode suprir algumas das necessidades abordadas, já que possibilita ao aluno ter acesso ao uso real da língua, em vez de somente recorrer aos exemplos das gramáticas que são, de modo geral, construídos a partir de um paradigma gerativista.

Nesse sentido, Costa e Miranda pontuam como

[...] vantajosa a utilização de corpora na investigação da linguagem, não só por oferecer acesso a informações inacessíveis a introspecção do pesquisador, mas também por permitir descrições mais precisas, e reais, de um determinado objeto, já que as informações emergem naturalmente dos dados (2011, p. 168).

Outro aspecto a ser destacado é o ensino do léxico. A aprendizagem desse conteúdo é de extrema importância para os alunos, já que a partir do conhecimento desse, o discente consegue se comunicar com maior eficácia, do que se dominar somente as habilidades gramaticais.

Adquirir um segundo idioma também exige a compreensão das "combinações de palavras", responsáveis por oferecer um entendimento mais complexo da linguagem dos falantes nativos. Captar o significado de expressões idiomáticas, 
colocações, provérbios, entre outros fraseologismos faz com que $o$ aluno, efetivamente, amplie o conhecimento cultural e linguístico.

Segundo Venturi (2006), é importante alternar entre itens lexicais e gramaticais, pois, paulatinamente, os estudantes apreendem os tópicos mais densos das duas vertentes. Por isso, destaco abaixo algumas pesquisas que utilizam corpora para tratar do ensino de LE:

- Oliveira, Orenha-Ottaiano e Alves (2017) aplicaram uma atividade de tradução aos alunos de uma escola particular de idiomas. Com as versões produzidas por estudantes de uma das histórias em quadrinhos digitalizadas, os autores investigaram as escolhas lexicais para a realização da tarefa, analisando itens lexicais e expressões idiomáticas traduzidos da língua portuguesa para a inglesa.

- Dutra e Silero (2010) trazem a ocorrência da palavra for em textos argumentativos, redigidos por universitários brasileiros. Ainda traz em seu bojo sugestões de atividades pedagógicas a partir dos dados coletados.

- Souza, Orenha-Ottaiano e Oliveira (em avaliação) também utilizam os estudos da LC aliado a corpora eletrônico para demonstrar como elaborar uma sequência didática em língua inglesa. Contudo, o mote das atividades ocorre a partir da utilização de dois corpora online de falantes nativos, usados para tratar da estrutura gramatical I'm going to e I'm going to.
Esses trabalhos demonstram a importância de trazer para o debate textos autênticos, responsáveis por motivar os alunos a perceber os padrões léxico-gramaticais presentes nos vernáculos. Além disso, são inovadores por proporem materiais autênticos de ensino, já que de um modo geral, os alunos possuem dificuldade de interagir em LE sem o uso do material didático impresso ou audiovisual fornecido pelas escolas.

Deve-se considerar a relevância dessa área na articulação de materiais que ofereçam subsídio para o ensino de idiomas. Nesse contexto, de acordo com o direcionamento dos corpora analisado, têm-se abordagens distintas, como o Data Driven Learning - DDL (JOHNS, 1991), Lexical Syllabus (WILLIS, 1990) e o Lexical Approach (LEWIS, 2000).

Além disso, o docente deve atuar de forma efetiva na elaboração de atividades que desenvolvam a reflexão e criticidade esperadas para a faixa etária dos alunos.

Para ilustrar uma pesquisa brasileira sobre este tópico cito Orenha-Ottaiano (2012, 2016), que por sua vez, versa sobre exercícios de LE dispostos no Online English Collocations Workbook ${ }^{2}$, enfocando diversas atividades elaboradas por meio da compilação de corpora de aprendizes, que são textos de universitários coletados para fins didáticos. A proposta é inovadora por explorar colocações de língua geral e também especializada, além de divulgar os resultados a alcance global, por meio da plataforma. 


\section{A magia de Harry Potter na sala de aula}

A série de livros sobre a saga de Harry Potter iniciou-se em 1997 com a publicação do livro Harry Potter and the Sorcerer's Stone na Inglaterra. Durante dez anos, a autora J. K. Rowling escreveria mais seis livros acerca da vida do personagem.

A história inicial mostra um garoto criado pelos tios. Ao completar 11 anos, ele recebe uma carta-convite da Escola de Magia e Bruxaria de Hogwarts e toma conhecimento de um mundo totalmente diferente, com a presença de seres fantásticos e a existência de magia, algo que ele desconhecia existir.

Cada livro representa um ano de vida do personagem principal. Dessa forma, o tempo ocorre de forma cronológica, mostrando os conflitos psicológicos, sociais e escolares típicos de um adolescente (dos 11 aos 17 anos de idade).

De acordo com a reportagem da Veja,

A saga impressa de Harry Potter vendeu mais de 400 milhões exemplares em todo o mundo, 3 milhões deles no Brasil e foi traduzida para 69 idiomas. O livro mais vendido da série foi o primeiro, com cerca de 120 milhões de vendas (2010, não paginado).

O sucesso editorial ocasionou as versões dos livros para o cinema e uma série de produtos licenciados sobre o tema. $\mathrm{O}$ interesse pela história atraiu tanto crianças quanto adultos, o que torna a saga um fenômeno mundialmente conhecido.
Nesse trabalho, optou-se por utilizar o primeiro livro em inglês, concomitante as imagens do respectivo filme no idioma original. Essa escolha justifica-se devido à apresentação do mundo mágico aos leitores e ou expectadores, além do próprio personagem da história.

Além disso, o fato do protagonista sair da infância e adentrar a adolescência, concomitantemente ao momento em que entra no ambiente mágico, escola de magia e bruxaria de Hogwarts, onde conhece pessoas e seres fantásticos intriga e cativa a atenção dos alunos.

Por isso, as atividades mostram temas voltados a escola de Magia Hogwarts, como a Carta de Aceite, lista de materiais, esportes praticados pelos bruxos e outros itens com os quais os alunos podem se identificar ou apreciar desse universo.

Contudo, a fim de atingir os objetivos propostos com o uso da tecnologia, o professor necessita oferecer elementos suficientes para que o aluno compreenda o uso das ferramentas computacionais e consiga realizar as conexões adequadas entre o corpus de pesquisa e as inferências cognitivas desejadas. Esse assunto será tratado com mais detalhes no próximo tópico, denominado Metodologia.

\section{Metodologia}

Esta etapa do texto visa a descrever os procedimentos metodológicos utilizados nesta pesquisa, bem como a maneira pela qual apresentamos a LC ao grupo de estudantes do curso English for teens. 
A aula completa foi aplicada em dois dias (7 e 9 de julho de 2016) em uma das salas do Unesp/Ibilce (Universidade Estadual Paulista "Júlio de Mesquita Filho"/ Instituto de Biociências, Letras e Ciências Exatas - São José do Rio Preto). Atendemos os alunos do curso English for Teens, adolescentes estudantes de escola pública de São José do Rio Preto, na faixa etária aproximada de 11 a 13 anos de idade. As aulas são monitoradas por uma aluna do curso de graduação de Letras, orientadas pela professora Dra. Adriane Orenha Ottaiano.

\section{Análise dos dados compilados: livro e legenda do filme}

O presente tópico descreve a análise realizada pelas pesquisadoras a fim de proceder a busca e o desenvolvimento de atividades relacionadas ao tema Harry Potter. Ao privilegiar as unidades padrões de léxico-gramática nas aulas de idiomas, pode-se quantificá-las e aferir reflexões sobre esses dados graças às análises com corpora.

Salientamos a utilização de contextos da língua em uso, haja vista que facilita o entendimento do aluno, concomitantemente ao aumento do seu léxico e as hipóteses que elabora sobre o idioma-alvo. Dessa forma, apresentamos alguns estudos comparativos entre o livro Harry Potter and the Sorcerer's Stone e as legendas do filme.

Tanto o livro quanto as legendas foram compilados em formato eletrônico de texto, extensão txt, para que o software WordSmith Tools (SCOTT, 2012) gerasse listas de palavras e concordâncias, a fim de que as analisássemos de forma rápida e precisa.

A partir dos dados observados, elaboramos dois esquemas gráficos para facilitar a leitura das informações encontradas. A Tabela 1 informa sobre os dados dos corpora de estudo e de referência utilizados na pesquisa:

Tabela 1 - Dados de corpora e de referência

\begin{tabular}{l|l|r|r|r}
\hline CORPUS & \multicolumn{1}{|c|}{ COMPOSIÇÃO } & PALAVRAS & FORMAS & TYPE/TOKEN RATIO \\
\hline Estudo & Livro & 80.635 & 5.718 & 7.09 \\
Estudo & Legendas do filme & 8.753 & 1.648 & 18.83 \\
Referência & Wordlist British National Corpus & 97.860 .872 & 512.588 & 0.52 \\
\hline
\end{tabular}

Fonte: dados estatísticos gerados pela ferramenta Wordlist do programa WordSmith Tools.

Baseado na Wordlist do British $\mathrm{Na}$ cional Corpus, a análise iniciou-se com a observação da densidade lexical do número global de palavras (nomeado tokens) e também do número de palavras diferentes (designada types).
É digna de nota a diferença entre as palavras do livro e do filme: 71.882 vocábulos. Apesar desta diferenciação, a obra escrita apresenta menor variação léxica do que o filme, indicado no item Type / Token Ratio (livro: 7.09 / legendas: 18.83). 
A explicação para esse fato linguístico reside nas diferenças entre as mídias analisadas. Ao contrário do material escrito (que descreve com minúcias de detalhes cada item existente no mundo mágico, as ações ocorridas e os pensamentos dos personagens), a película apresenta estes mesmos aspectos visualmente (com o uso de efeitos especiais, por exemplo). Dessa maneira, torna-se desnecessária a repetição de nomes, lugares e expressões ocorridas no texto; e retomados por imagens no filme.

Em relação à lista de palavras-chave (KeyWords), os resultados são:

Tabela 2 - KeyWords das 20 primeiras palavras

\begin{tabular}{|c|c|c|c|c|c|c|c|}
\hline \multicolumn{4}{|c|}{ Livro 01} & \multicolumn{4}{|c|}{ Legendas do filme 01} \\
\hline $\mathrm{N}$ & Word & Freq. & $\%$ & $\mathrm{~N}$ & Word & Freq. & $\%$ \\
\hline 1 & HARRY & 1,327 & 1.65 & 1 & 1 & 11,697 & 57.20 \\
\hline 2 & $S$ & 1,015 & 1.26 & 2 & $\mathrm{~L}$ & 203 & 0.99 \\
\hline 3 & $\mathrm{~T}$ & 841 & 1.04 & 3 & $\mathrm{LT}^{\prime} \mathrm{S}$ & 45 & 0.22 \\
\hline 4 & HAGRID & 370 & 0.46 & 4 & $L^{\prime} M$ & 42 & 0.21 \\
\hline 5 & RON & 429 & 0.53 & 5 & HARRY & 70 & 0.34 \\
\hline 6 & HERMIONE & 271 & 0.34 & 6 & HAGRID & 24 & 0.12 \\
\hline 7 & DIDN & 199 & 0.25 & 7 & DUMBLEDORE & 21 & 0.10 \\
\hline 8 & DUMBLEDORE & 160 & 0.20 & 8 & POTTER & 37 & 0.18 \\
\hline 9 & SNAPE & 171 & 0.21 & 9 & HOGWARTS & 20 & 0.10 \\
\hline 10 & $\mathrm{HE}$ & 1,759 & 2.18 & 10 & $L^{\prime} V E$ & 17 & 0.08 \\
\hline 11 & LL & 161 & 0.20 & 11 & GRYFFINDOR & 16 & 0.08 \\
\hline 12 & MALFOY & 128 & 0.16 & 12 & SLYTHERIN & 14 & 0.07 \\
\hline 13 & VE & 180 & 0.22 & 13 & YOU & 321 & 1.57 \\
\hline 14 & QUIRRELL & 113 & 0.14 & 14 & HERMIONE & 17 & 0.08 \\
\hline 15 & YEH & 122 & 0.15 & 15 & SNAPE & 17 & 0.08 \\
\hline 16 & COULDN & 106 & 0.13 & 16 & FLAMEL & 11 & 0.05 \\
\hline 17 & MCGONAGALL & 100 & 0.12 & 17 & VOLDEMORT & 10 & 0.05 \\
\hline 18 & DUDLEY & 140 & 0.17 & 18 & QUIDDITCH & 9 & 0.04 \\
\hline 19 & DON & 175 & 0.22 & 19 & MALFOY & 8 & 0.04 \\
\hline 20 & SAID & 794 & 0.98 & 20 & $L^{\prime} L L$ & 8 & 0.04 \\
\hline
\end{tabular}

Fonte: lista de dados gerada pelo software WordSmith Tools.

Novamente, o que justifica a alteração dos dados é a natureza das fontes pesquisadas. Como exemplo da diferença, tome-se o nome do protagonista: a palavra Harry é citada 1.327 vezes no texto escrito, porém a ocorrência nas legendas do filme é quase nula (se comparada à primeira lista) - apenas 70 vezes. Visto que só a imagem do personagem mos- trada na tela já retoma o protagonista sem que esse precise ser mencionado verbalmente. A obra escrita, ao contrário, necessita utilizar constantemente recursos anafóricos para conseguir este efeito, como: he (1759 ocorrências); his (936 vezes) e Potter (104 repetições), por exemplo. 
Torna-se oportuno efetuar alguns apontamentos sobre as escolhas lexicais efetuadas nas atividades, conforme indicam as linhas de concordância a seguir:

Figura 1 - Algumas linhas de concordância do vocábulo school

\section{Concordance}

them outside. 'I bet you'll think twice about breaking a school rule again, won't you, eh?' he said, leering at they're doing, keeping a thing like that locked up in a school?' said Ron finally. "If any dog needs exercise, a giant called Hagrid came to tell me I was going to a school for wizards. When I open my eyes III be at a name he had found in A History of Magic. His school books were very interesting. He lay on his bed inform you that you have been accepted at Hogwarts School of Witchcrat and Wizardry. Please find

die. Mr. Potter, do you know what is hidden in the school at this very moment? The Sorcerer's Stonel

Fonte: Print da ferramenta Corcondance, tela do software WordSmith Tools.

A palavra school aparece 63 vezes na obra textual, ora retratada como um local de ensino, ora destacando os elementos mágicos existentes no contexto. É válido lembrar que o nome da escola Hogwarts possui 79 entradas e pode ser considerada uma metonímia para escola. Portanto, sua importância dentro do contexto do livro é bastante representativa, visto que todas as ações principais ocorrem dentro do castelo.

Outra palavra relacionada a esse universo é magic, com 59 repetições. A palavra mais utilizada com magic é o verbo $d o$ (e variações):

Figura 2 - Recorte de itens lexicais recorrentes com o vocábulo magic

\begin{tabular}{|r|r|r|}
\hline 6 & History of Magic by Bathilda Bagshot Magical Theory by Adalbert Waffling A \\
7 & in here - they thought I might not be magic enough to come, you see. \\
8 & of the most complex and dangerous magic you will learn at Hogwarts," she \\
9 & with a broomstick except powerful Dark magic - no kid could do that to a \\
10 & the books containing powerful Dark Magic never taught at Hogwarts, and \\
11 & said. "I'm - er - not supposed ter do magic, strictly speakin'. I was allowed \\
12 & and then he gets drunk, tries to do magic, and ends up setting fire to his \\
13 & job." "Why aren't you supposed to do magic?" asked Harry. "Oh, well - I \\
14 & wand in his hand. "Oh, are you doing magic? Let's see it, then." She sat \\
\hline
\end{tabular}

Fonte: Print da ferramenta Corcondance, tela do software WordSmith Tools.

Logo, observa-se que o estudo das linhas de concordância auxilia muito o aluno observar a língua-alvo em uso. A partir do exposto, nota-se que o professor possui um arsenal imenso a explorar. 
Após a análise dos dados baseados nos corpora coletados, explanaremos neste tópico, as atividades preliminares para o entendimento sobre corpora transmitido aos discentes, e ainda a descrição sucinta das duas aulas, bem como os exercícios propostos e ministrados no curso de Extensão English for Teens.

\section{Introdução ao tema e apresentação da LC aos estudantes}

Como já citado na fundamentação teórica, o trabalho com corpora exige um cuidado redobrado do docente, não só em planejar aulas de acordo com a faixa etária e que esteja no nível dos estudantes, mas, também, um preparo especial em abordar o tema de forma clara e funcional.

Visto que todos já conheciam a história de Harry Potter, incluindo livros, filmes e jogos de videogame sobre o tema - e considerando a extensão do filme (159 minutos), não assistimos a película mencionada.

A ambientação para a aula ocorreu, por sua vez, a partir da exposição de alguns objetos de nossa coleção pessoal presentes no ambiente mágico de Harry Potter, como: varinha do mágico com imã (que atrai objetos de metal), vira-tempo (um dos motes da trama do terceiro livro), peças de xadrez bruxo desmontáveis ao toque, abóboras de plástico e doces distribuídos ao longo da aula.

Os alunos gostaram bastante de interagir com os objetos sempre citados em inglês durante os minutos iniciais. Em seguida, começamos a tratar de LC propriamente dita.

Nesse âmbito, trazemos as contribuições de Sripicharn (2010), ao sugerir atividades introdutórias de LC antes de iniciar qualquer análise em sala de aula:

Uma vasta gama de técnicas de pesquisa pode ser usada para obter informações sobre o que os alunos já conhecem sobre o tema (diagnóstico inicial). O professor pode começar a aula com uma discussão em classe pedindo aos alunos para relatar o que eles sabem sobre a linguagem corpora e sua experiência de usá-los. Além de uma discussão oral, questionários, listas de verificação ou testes podem ser administrados para dar ao professor algumas ideias sobre o conhecimento prévio dos alunos em relação com o corpus $(2010$, p. 371$){ }^{3}$

Para esse fim, foram elaborados dois textos: o primeiro, de ordem introdutória:

- conceitos de fácil entendimento sobre a LC e o software WordSmith Tools;

- alguns testes para observar a probabilidade linguística dos alunos.

O segundo, de cunho avaliativo, foi aplicado ao final do segundo encontro, teve o objetivo de incitar a opinião do aluno acerca da aula realizada e solicita sugestões de outras mídias a serem usadas nas aulas de inglês.

O texto introdutório foi responsável por iniciarmos o diálogo acerca dos objetivos da LC com os estudantes no começo do primeiro encontro. A partir da leitura desse, questionamos oralmente se já haviam ouvido falar dessa vertente linguística. 
Figura 3 - Atividade preliminar - Texto introdutório

\section{Harry Potter e o Programa WordSmith Tools}

É possivel saber quantas vezes uma palavra aparece em um livro ou texto de vánas maneiras. Uma forma seria contarmanualmente (página por página), marcando os resultados. Outra (muto mais prática) é usar programas de informática que mostram esses dados, como o programa WordSmith Tools.

Ao insenimos um arquivo de texto neste software, ele retoma diversas informações interessantes, que ajudam as anälises enos fazem perceber quais palavras e personagens são mais usados pelo autor. Além disso, é possivel sabermos melhor o funcionamento das expressões em inglês, como phrasal verbs, por exemplo.

Fonte: das autoras.

Todos os alunos desconheciam LC e tudo o que estava relacionado a esse universo. Contudo, a surpresa em saber que existem programas que fazem a contabilização dos dados deixou os jovens entusiasmados com o que exatamente poderíamos realizar nos dois encontros.

Assim, passamos ao segundo tópico, a administração de um questionário. Esse foi importante para verificarmos o que os alunos entendem por probabilidade linguística e léxico-gramatical, encontradas no primeiro livro da saga de Harry Potter.

Discutiremos o desempenho dos estudantes acerca do questionário no tópico analítico, denominado "Resultados e discussão do desempenho dos alunos".

Prosseguindo com o relato das aulas, após a introdução do assunto, iniciamos a execução das tarefas, conforme segue no próximo subitem.

\section{Harry Potter na sala de aula: descrição dos exercícios}

Na primeira atividade, os estudantes preencheram um envelope, tal como o recebido pelo protagonista no início da história, ou seja, com informações de si próprio. Além disso, o propósito da atividade é instigar o grupo a utilizar a preposição correta (on, in, under, in front of, behind) ao descrever a localização em que se encontram dentro da casa (a partir da referência de Harry na casa dos tios: The cupboard under the stairs). Essa tarefa atua como uma introdução ao tema, pois possibilita que o estudante se coloque no lugar do personagem, se sentindo parte da narrativa.

A segunda página é uma cópia da carta recebida por Potter convidando-o a 
frequentar a escola de Magia e Bruxaria de Hogwarts. Há várias lacunas a serem preenchidas, e para tal, o discente deve escolher entre duas opções. O desafio é diferenciar a linguagem informal da formal, já que a carta foi escrita pelo diretor da escola, Albus Dumbledore. A título de exemplificação, seguem alguns trechos: "(Director / Headmaster):

ALBUS DUMBLEDORE"; "We are (happy/pleased) to inform you that you have been accepted at Hogwarts School of Witchcraft and Wizardry." e "Yours (carefully/sincerely) ".

Na terceira folha, é apresentada a lista de materiais escolares, conforme segue:

Figura 4 - Atividade 03

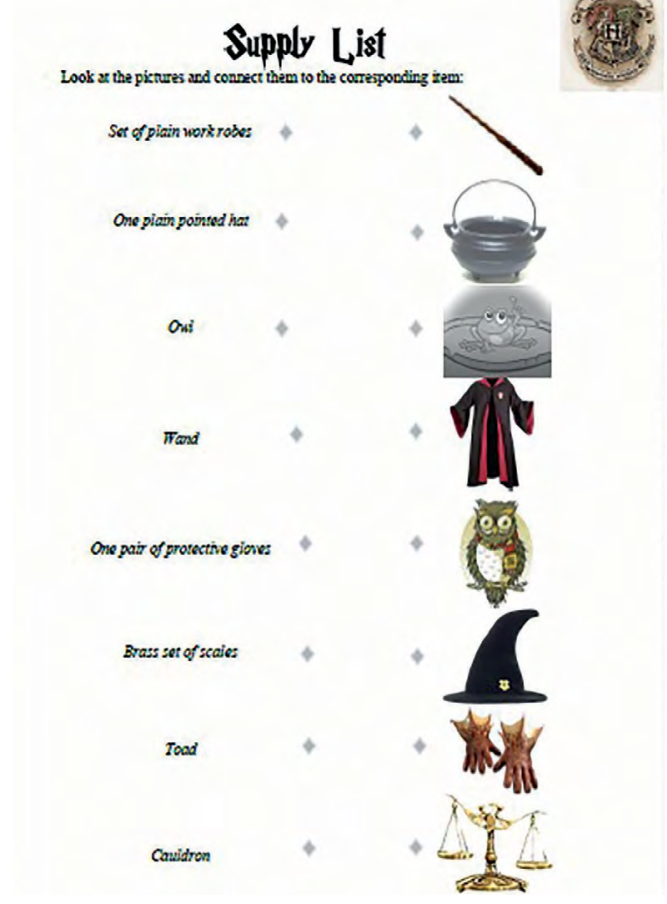

Fonte: das autoras.
Solicita-se a relação entre a escrita dos itens e a figura representativa desses. A exploração lexical é interessante por dar a oportunidade ao aluno de entrar em contato com um vocabulário específico de um texto fantasioso, embora possua itens que podem ser utilizados em uma lista do mundo real, como set of plain work robes, one pair of protective gloves, por exemplo.

A quarta atividade traz um trecho do filme citado. Após assisti-los, o educando deve pautar a ordem dos acontecimentos, além de responder um pequeno teste com questões sobre a cena. Dentre essas, destaca-se a de ordem colocacional, como a raça de gato que a professora $M c G o$ nagall se transfigura: tabby, siamese ou persian.

A quinta e sexta atividades estão interligadas, já que a primeira apresenta um Word Find, com dezoito palavras, a maioria delas referentes ao campo semântico de aniversário - visto que o filme inicia-se no dia do nascimento do protagonista. A próxima, por sua vez, mostra alguns lexemas da lista anterior embaralhadas.

A página seguinte é uma cruzadinha, com perguntas acerca dos títulos e personagens dos livros. É uma atividade simples, porém visa a aguçar a curiosidade dos alunos sobre a sequência da história apresentada nesse primeiro livro.

As duas últimas folhas remetem à escrita: a penúltima pede uma descrição sobre as características físicas e aspectos psicológicos de quatro personagens, enquanto a última solicita um 
parágrafo acerca do que o aluno espera encontrar em uma escola de magia sobre o intervalo, aulas, professores, dentre outros aspectos. Ao término, sugerimos a socialização do relato escrito para os colegas de sala.

Desse modo, as atividades relatadas possuem estratégias diferentes, a fim de instigar o estudante a otimizar diferentes habilidades: ler, escrever, ouvir e falar. Nesse sentido, as tarefas mostram a capacidade de utilização de corpora a fim de trabalhar as capacidades comunicativas em língua inglesa de forma lúdica e interessante, conforme atestam os resultados das atividades, explicitadas na sequência.

\section{Análise dos resultados e discussão do desempenho dos alunos}

Este item trata sobre como os discentes se relacionaram com os exercícios, tanto os de cunho diagnósticos quanto aqueles versados ao conteúdo da temática Harry Potter.

Conforme dito na metodologia, iniciamos a análise com um texto introdutório sobre LC e o software WordSmith Tools, além da aplicação de um questionário cujo objetivo é fomentar a curiosidade dos alunos frente a LC, enquanto examinamos de que maneira os jovens percebem os padrões léxico-gramaticais da língua inglesa.

Durante todas as aulas, os discentes se mostraram bastante atentos às explicações, interagindo conosco a leitura e discussão do texto inicial. Esse fato nos indica que os jovens se verdadeiramente se interessam quando o assunto envolve tecnologia. Ainda mais por desconhecerem a LC e suas implicações para o ensino, consideramos a interação positiva e profícua no intento de introduzir o tema.

Já o conteúdo das cinco perguntas pertencentes ao questionário segue na próxima página:

Figura 5 - Atividade preliminar - Questionário

Responda ao teste abaixo e verifique como estão as suas noções de probabilidade.

1. Aproximadamente, há quantas palavras no livro "Harry Potter and the Sorcerer"s Stone"? Observação: o livro possui 320 páginas.
A) 5.300
B) 47.000
C. 80.600

2. Qual é a palavra mais escrita no livro "Harry Potter and the Sorcerer's Stone"?
A) Hamy
B) The
C) Professor

3. Quantas vezes a palavra Wizard (Bruxo) aparece neste livro?
A) 539
B) 122
C) 48

4. Qual é o professor mais citado na obra?

$\begin{array}{ll}\text { A) McGonagall } & \text { B) Snape }\end{array}$

C) Madam Hooch

5. Qual frase mostra o uso correto da palavra "Make"?

A. (...) and Make a cup of tea.

B. Make it again, Dudley ordered.

C. Make you want to stop Snape or not?

Fonte: das autoras. 
Os discentes tiveram mais facilidade em responder as questões 1 e 4 ; e dificuldades para identificar as respostas das perguntas 2, 3 e 5. Após as indagações orais sobre as justificativas para as escolhas dos alunos, fizemos a correção mostrando as telas do programa informatizado supracitado aos alunos, comprovando empiricamente as resoluções.

Seguem abaixo algumas imagens das telas do programa utilizado nesta pesquisa, justificando as soluções corretas e também algumas hipóteses que levantamos dessa interessante experiência:

Figura 6 - Resolução da questão \#01

\begin{tabular}{|c|c|c|}
\hline $\begin{array}{l}\text { tokens } \\
\text { (running } \\
\text { words) in }\end{array}$ & $\begin{array}{l}\text { tokens } \\
\text { used for } \\
\text { word list }\end{array}$ & types (distinct words) \\
\hline 80,658 & 80,635 & 5,718 \\
\hline
\end{tabular}

Fonte: Print da ferramenta Wordlist, tela do software WordSmith Tools.

O fato de o livro ter 320 páginas, fez com que todos os discentes acertadamente supusessem que o total de palavras seria o maior número dentre as opções apresentadas, levando-os a escolherem a letra $\mathrm{C}$.

Nesse caso, a intuição linguística estava intrinsecamente relacionada a fatores de dedução e lógica. Um dado adicional que apresentamos aos alunos é a respeito dos tokens e types, já citados neste texto anteriormente (o primeiro é o número global de palavras, enquanto o segundo diz respeito às formas, ou seja, os vocábulos sem repetição). Os discentes se mostraram surpresos com o número de palavras inéditas, pois acreditavam que seria muito maior do que o exposto pelo programa, conforme apontado na Figura 6.

Sobre a segunda pergunta, segue 0 print da tela do software, na sequência:

\section{Figura 7 - Resolução da questão \#02}

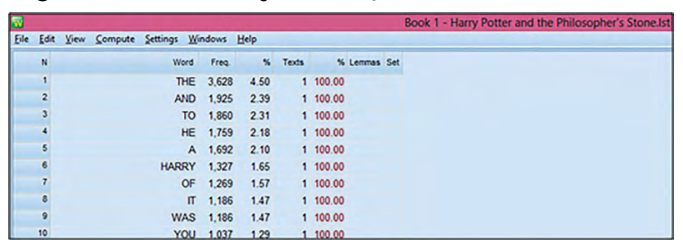

Fonte: Print da ferramenta Wordlist, tela do software WordSmith Tools.

Já na segunda questão, observamos que houve discrepância entre as respostas apresentadas, já que enquanto alguns afirmavam que a palavra mais redigida no livro era Harry (letra A), outros consideravam o artigo definido the (Letra B) a alternativa ideal.

Temos aqui, especificadamente, a aplicação de uma das circunstâncias apontadas pelo acessório do WordSmith Tools, Wordlist: visto que indica os vocábulos mais reiterados, os primeiros itens da lista serão predominantemente gramaticais, representados por pronomes, artigos e preposições.

Figura 8 - Resolução da questão \#03

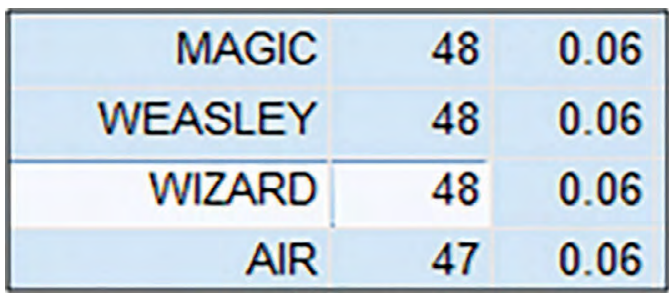

Fonte: Print da ferramenta Wordlist, tela do software WordSmith Tools. 
Outra divergência ocorreu na terceira etapa, sobre quantas vezes a palavra Wizard aparece no livro (a probabilidade apontada foi superior a real). Isso demonstra que os discentes não consideraram os sinônimos para o vocábulo bruxo, como sorcerer, magician, wizardry, por exemplo, ou ainda que os personagens podem ser referenciados pelo nome próprio, além dos pronomes pessoais you, he, she, we, they.

A quarta questão também foi solucionada com facilidade, sobre o professor mais citado - por unanimidade, o mago Snape, demonstrando que os estudantes conhecem (de fato) a história de Harry Potter e sua relação particularmente difícil com o professor de Poções.

Por fim, na pergunta gramatical, os discentes apresentaram dificuldades em respondê-la, pois a alternativa A não foi apontada como a correta. Para corrigi-la, foi necessário mostrar que, de acordo com o uso do verbo make, a frase Make it again, Dudley ordered não poderia ocorrer; já que esta forma é mais adequada com o verbo $d o$.

No momento da aferição das respostas, tivemos a oportunidade de conversar a respeito da importância em conhecer as ferramentas proporcionadas pela LC, visto que todas as respostas eram plausíveis de ser encontradas neste software.

Outra observação digna de nota diz respeito à reação dos estudantes. Esses ficaram impressionados com essa "nova" possibilidade de estudar inglês, até então desconhecida por eles.

\section{Sobre o desempenho dos alunos nas atividades}

Observou-se que os alunos não tiveram dificuldades com o uso das preposições na atividade 1 , ao contrário do que foi previamente imaginado na elaboração do material, denotando que este tópico foi bem apreendido pelos discentes.

Na Folha 2, da escolha lexical para o preenchimento de carta formal, os discentes apresentaram algumas dúvidas tangente ao vocabulário: headmaster, pleased, surrogate e deputy as quais foram palavras consideradas difíceis para a classe.

No próximo exercício, a maioria das palavras foi relacionada com êxito, exceto a locução brass set of scales, apontada por dedução ou pela exclusão de outras imagens. $\mathrm{O}$ quarto exercício proposto, Listening and Comprehension foi outro que surpreendeu pela parcial facilidade em identificar a ordem dos acontecimentos. Ao questionar o critério para a anotação dos números, os alunos foram unânimes em afirmar que observaram o nome dos personagens nas frases e alguns verbos, como begins, fly, transfigurates e fall.

Foi necessário, entretanto, apresentar o vídeo uma segunda vez, para que fossem sanados os questionamentos sobre: o momento em que Malfoy rouba o Remembrall; o tipo de gato em que a professora McGonagall se transforma; verificar a fala da professora Madam 
Hooch acerca da parte do corpo que $\mathrm{Ne}$ ville quebrou ao cair da vassoura.

As próximas atividades relacionadas tiveram um resultado interessante: enquanto a Word Find (Atividade 5) fora realizada com êxito; na Folha 6 Scrambled Word Game os estudantes não conseguiram desembaralhar as palavras 8, 11 e 12 (respectivamente SNACKS, STREAMERS e DECORATIONS) - não relacionadas na página anterior.

A página 7 Crossword Puzzle foi considerada difícil, pois traz em seu bojo informações sobre outros filmes da saga Harry Potter.

Com a proximidade do término da aula, infelizmente a página 8 e 9 não foi trabalhada na íntegra durante a segunda aula. Observamos, contudo, que a possibilidade de imaginar uma escola de magia na realidade ocasionou momentos de riso na aula, na escrita do relato, com alunos voando pelo pátio ou professores explodindo na sala.

Devido ao número de páginas ser extenso, as páginas 8 e 9 foram deixadas como tarefa, a serem finalizadas pelos alunos em casa e, posteriormente, trabalhadas em aula, com a leitura em grupo dos itens redigidos, além da correção realizada pela professora da turma.

\section{A aplicação do Questionário 2: pesquisa de opinião}

Um segundo questionário foi aplicado ao final do último dia com cinco questões dissertativas. $\mathrm{O}$ objetivo dessa última atividade é possibilitar um feedback escrito da aula apresentada. A primeira pergunta questiona se os alunos gostaram das atividades do livro/filme de Harry Potter e quais páginas baseadas em corpora mais lhes agradaram. A aprovação foi universal, com destaque para as folhas sobre Supply List, Word Find, Crossword Puzzle e Writing.

$\mathrm{Na}$ sequência, é solicitado que escrevam ao menos cinco palavras ou expressões que aprenderam durante as aulas. As mais indicadas foram: wand; toad; brass set of scales; streamers e headmaster.

A terceira indagação é sobre o uso do programa WordSmith Tools. As respostas indicam o que os estudantes acharam "poder saber cada detalhe de um texto"; "interessante sobre as estatísticas"; "é uma ferramenta incrível e pode ajudar muito".

O quarto ponto questiona se o uso de livros ou filmes nas aulas de inglês facilita a aprendizagem. Novamente as réplicas foram positivas, conforme atestam os trechos: "Sim, torna a aula mais divertida e gostando das aulas a aprendizagem é bem mais produtiva."; "Pois é uma maneira diferente de aprender novos vocabulários, além de ser interativo"; "Sim, nos livros e filmes em inglês pode existir o conteúdo da matéria".

Na última parte, pede-se sugestões de mídias que poderiam ser temas de aulas em inglês. Dentre as ideias apresentadas, estão: Final Fantasy, Adventure Quest World, Dark Souls II (jogos de videogame no estilo RPG); Friends, The 
Big Bang Theory (séries de televisão americanas).

\section{Conclusão}

A aceitação dos alunos ao conteúdo proposto foi incontestável desde o início do trabalho. Conforme já exposto em diversos pontos desta pesquisa, o professor necessita saber como conduzir sua aula, de forma a deixar os seus estudantes seguros, interessados e motivados em aprender.

Nas atividades avaliativas, os discentes lamentaram o fato de seus colegas e professores da sala regular desconhecerem as ferramentas vistas no Ibilce. Infelizmente, ainda são poucos os docentes de LE que têm conhecimento do universo da LC e das vantagens em explorar o corpus eletrônico em sala.

Em trabalhos posteriores, seria interessante pesquisar quais formas pode-se expandir a divulgação desse tema de forma profícua e global. Dessa maneira, outras investigações sobre a aprendizagem movida por dados poderiam ser realizadas. Com a divulgação de novos trabalhos, quem sabe, possivelmente poderíamos atingir melhores resultados no ensino de segunda língua, possibilitando, dessa maneira, um novo patamar na aprendizagem desse segmento tão importante no mundo globalizado em que vivemos.
Harry Potter and the Corpus Linguistics classes in English for Elementary Education II

\section{Abstract}

The article describes the performance of classes of English based on the first book and movie of the saga written by Joanne Kathleen Rowling's "Harry Potter and the Sorcerer's Stone" in corpora. The research uses postulates of Corpus Linguistics and the use of methodologies in the teaching of foreign language. The software WordSmith Tools, version 6.0 was used to corroborate the information of two comparable corpora (book scanned and legends of film in electronic format). From the information collected, developed a material composed for activities to teach English. Some of these activities were implemented in the extension course (English for Teens), a public university, whose target audience are students from public schools, from Elementary Education II.

Keywords: Corpora. Foreign Language. Methodology. Harry Potter.

\section{Notas}

1 As aplicações de LC são realizadas com maior ênfase na Aprendizagem de LE, Estudos da Tradução, Corpora de Aprendizes, Fraseologia de língua geral e especializada, dentre outras vertentes. Para os interessados em se aprofundar nestes tópicos, segue um pequeno rol de autores especializados nas temáticas citadas: Sinclair (1997); Granger; Hung; Petch-Tyson (2002); McEnery; Xiao; Tono (2006); Orenha-Ottaiano (2004; 2009); Viana (2010); O’Keeffe; McCarthy (2010); Tagnin (2015). 
2 Para acessar a website, o link é: <http://www. institucional.grupogbd.com/workbook/index>. Acesso em: 4 jul. 2017.

3 No original: "A wide range of survey techniques can be used to elicit information about learners' backgrounds. The teacher may begin a lesson with a class discussion asking the students to report what they know about language corpora and their experience of using them. Apart from an oral discussion, a written survey in the form of questionnaires, checklists or quizzes can be administered to give the teacher some ideas about learners' prior knowledge of corpus-related issues". As traduções são de responsabilidade das autoras.

\section{Referências}

BRASIL. Parâmetros Curriculares Nacionais: Língua estrangeira. Brasília: MEC/ SEF, 1998. Disponível em: <http://portal. mec.gov.br/seb/arquivos/pdf/pcn_estrangeira. pdf>. Acesso em: 04 jul. 2017.

BRASS_SCALES, PNG. Altura: 160 pixels. Largura 200 pixels. Formato PNG. Disponível em: <http://harrypotter.wikia.com/wiki/ Brass_scales?file=Brass-scales.png $>$. Acesso em: 4 mar. 2016.

CAULDRON, JPEG. Altura: 302 pixels. Largura 360 pixels. Formato JPEG. Disponível em: <http://fatoefarsa.blogspot.com. br/2013/06/caldeirao-consideracoes-sobre-peca.html>. Acesso em: 5 mar. 2016.

COSTA, I. O.; MIRANDA, N. S. A construção superlativa de expressão corporal: uma análise baseada em corpora. In: DUTRA, D. P.; MELLO, H. R. (Org.). Anais do X Encontro de Linguística de Corpus: aspectos metodológicos dos estudos de corpora. Belo Horizonte: Faculdade de Letras da UFMG, 2011. p. 158-171.

CURIOSIDADES numéricas da saga Harry Potter. Veja, 2010. Disponível em: <http:// veja.abril.com.br/noticia/celebridades/curiosidades-numericas-da-saga-harry-potter>. Acesso em: 30 jun. 2017.
DUTRA, D. P.; SILERO, R. P. Descobertas linguísticas para pesquisadores e aprendizes: a Linguística de Corpus e o ensino de gramática. Revista Brasileira de Linguística Aplicada, Belo Horizonte, v. 10, n. 4, p. 909-930, 2010.

ENVELOPE, JPEG. Altura: 425 pixels. Largura 368 pixels. Formato JPEG. Disponível em: <http:/www.originalprop.com/ blog/2009/02/05/les-hemstock-movie-used-harry-potter-envelope-warner-bros-coa/>. Acesso em: 6 mar. 2016.

FLAG Hogwarts, GIF. Altura: 256 pixels. Largura 289 pixels. Formato GIF. Disponível em: <http://jesus6409.wix.com/hpzcom>. Acesso em: 5 mar. 2016.

GLOVES, JPEG. Altura: 601 pixels. Largura 601 pixels. Formato JPEG. Disponível em: <http://gamingbolt.com/wp-content/ uploads/2012/09/21132Dragon_Hide_Gloves_Render.jpg>. Acesso em: 6 mar. 2016.

GRANGER, S.; HUNG, J.; PETCH-TYSON, S. (Ed.). Computer Learner Corpora, Second Language Acquisition and Foreign Language Teaching. Benjamins: Amsterdam, 2002.

HARRY Potter and the Sorcerer's Stone. Produção: David Heyman. Direção: Chris Columbus. Intérpretes: Daniel Radcliffe; Rupert Grint; Emma Watson. Reino Unido: Warner Bros. Pictures, 2001. DVD (159 min), son, color.

HARRY-Potter-costume, JPEG. Altura: 500 pixels. Largura 500 pixels. Formato JPEG. Disponível em: <http://gabtor.files.wordpress.com/2010/11/harry-potter-school-robe. jpg>. Acesso em: 6 mar. 2016.

HAT-hogwarts, JPEG. Altura: 370 pixels. Largura 370 pixels. Formato JPEG. Disponível em: <http://www.wbshop.com/category/wbshop_brands/harry+potter/hats. do?nType=2>. Acesso em: 4 mar. 2016.

HPM_1, JPEG. Altura: 490 pixels. Largura 369 pixels. Formato JPEG. Disponível em: <http://www.gorilapolar.com.br/wp-content/ 
uploads/2012/04/hpm_1.jpg>. Acesso em: 4 mar. 2016.

HPM_2, JPEG. Altura: 490 pixels. Largura 340 pixels. Formato JPEG. Disponível em: <http://www.gorilapolar.com.br/wp-content/ uploads/2012/04/hpm_2.jpg>. Acesso em: 5 mar. 2016.

HPM_6, JPEG. Altura: 490 pixels. Largura 340 pixels. Formato JPEG. Disponível em: <http://www.gorilapolar.com.br/wp-content/ uploads/2012/04/hpm_6.jpg>. Acesso em: 5 mar. 2017.

JOHNS, T. Data-driven learning: the perpetual challenge. In: KETTEMANN, B.; MARKO, G. (Ed.). Teaching and Learning by Doing Corpus Analysis. Amsterdam: Rodopi, 1991. p. 107-117.

LEWIS, M. Teaching Collocation: Further developments in the Lexical Approach. Hove, England: Language Teaching Publications, 2000 .

MCENERY, T.; XIAO, R.; TONO, Y. Corpus-based language studies: an advanced resource book. London: Routledge, 2006.

MINERVA-professor-mcgonagall, JPEG. Altura: 894 pixels. Largura 894 pixels. Formato JPEG. Disponível em: <http://images5. fanpop.com/image/photos/30000000/Minerva-professor-mcgonagall-30099491-894-894. jpg>. Acesso em: 6 mar. 2017.

O'KEEFFE, A.; MCCARTHY, M. J. (Ed.). The Routledge handbook of corpus linguistics. London: Routledge, 2010.

OLIVEIRA, Elaine Cristina; OTTAIANO, Adriane Orenha; ALVES, Vinícius Cineli. O léxico nas traduções de história em quadrinhos: uma experiência baseada em corpus. Entrepalavras, v. 7, n. 1, p. 141-159, set. 2017. Disponível em: <http://www.entrepalavras.ufc.br/revista/index.php/Revista/article/ view/846>. Acesso em: 15 nov. 2017.

ORENHA-OTTAIANO, A. A compilação de um glossário bilingüe de colocações, na área de jornalismo de Negócios, baseado em corpus comparável. 2004. Dissertação (Mestrado em Estudos Linguísticos e Literários) - FFLCH, Universidade de São Paulo, São Paulo, 2004.

Compilação de um corpus de aprendizes de tradução e análise de aspectos colocacionais. In: ABRALIN EM CENA, 2012. Anais... Cuiabá: Abralin, 2012.

. Learning and teaching collocations through an Online English Collocations Workbook. In: Vocab@Tokyo, 2016, Tóquio. Vocab@Tokyo conference Handbook, 2016. p. 59-60.

. Unidades fraseológicas especializadas: colocações e colocações estendidas em contratos sociais e estatutos sociais traduzidos no modo juramentado e não-juramentado. Tese (Doutorado em Linguística Aplicada) - Ibilce/Unesp, São José do Rio Preto, 2009.

OWL, JPEG. Altura: 646 pixels. Largura 929 pixels. Formato JPEG. Disponível em: <http:// fc01.deviantart.net/fs70/f/2013/224/e/1/449_ by_drud_studio-d6hw5w5.jpg>. Acesso em: 4 mar. 2017.

ROWLING, J. K. Harry Potter and the Sorcerer's Stone. London: Bloomsbury Children's, 1997.

SAPO, JPEG. Altura: 480 pixels. Largura 360 pixels. Formato JPEG. Disponível em: <https:/www.youtube.com/watch?v=0JkSpPZJDkE>. Acesso em: 5 mar. 2017.

SCOTT, M. WordSmith Tools. Versão 6.0. Oxford: Oxford University Press, 2012.

SINCLAIR, J. Corpus evidence in language description. In: WICHMANN, A. et al. (Ed.). Teaching and language corpora. London: Longman, 1997. p. 27-39.

SOUZA, G. A.; ORENHA-OTTAIANO, A.; OLIVEIRA, E.C.F. Uma proposta de aula baseada em corpora online para nível básico. Diálogo das Letras. Em avaliação.

SRIPICHARN, P. How can we prepare learners for using language corpora? In: O'KEEFFE, A.; MCCARTHY, M. (Ed.). The Routledge 
Handbook of Corpus Linguistics. London; New York: Routledge, 2010. p. 371-384.

TAGNIN, S. E. O. A linguística de Corpus na e para a tradução. In: VIANA, V.; TAGNIN, S. E. O. Corpora na tradução. São Paulo: Hub, 2015. p. 19-56.

VENTURI, M. A. Aquisição de língua estrangeira numa perspectiva de estudos aplicados. São Paulo: Contexto, 2006.

VIANA, V. Linguística de Corpus: conceitos, técnicas \& análises. In: VIANA, V.; TAGNIN, S. E. O. (Org.). Corpora no ensino de línguas estrangeiras. São Paulo: Hub, 2010. p. 25-96.

WAND, JPEG. Altura: 393 pixels. Largura 393 pixels. Formato JPEG. Disponível em: $<$ http://www.wbshop.com/category/wbshop_ brands/harry+potter/wands.do $>$. Acesso em: 4 mar. 2017.

WILLIS, D. The Lexical Syllabus. London: Collins, 1990. 